\title{
Comparative Study on Chinese and Canadian Education Policies for Trans-culture Immigrants
}

\author{
Changxing Zhao, Ruiqin Duan, Jie Zhang \\ College of Humanities, Xidian University, Xi'an, 710071, Chna
}

Keywords: China, Canada, Immigrants, Education Policy, Multi-culture

\begin{abstract}
The implementation of multi-cultural education promotes the prosperity and sustainable development of Canada; however the racial inequality is yet eliminated thoroughly. Under the mechanism of reversed pressure, China sets out to response to the education for migrant children, from passive to initiative, from restriction to openness, from difference to equality, from administration to service, keep improving policy level and right guarantee level. From an overall perspective of two countries' education policies for immigrants, they are highly consistent in maintain national stability, social harmony and racial equality, however, there is significance difference in the background, connotation, path and so on of polices due to the difference on historic culture and realistic national condition. China should rationally take Canada as a reference based on its actual situation.
\end{abstract}

\section{Introduction}

Canada is one of the most typical immigrant countries in the world. Immigrants constitute the major part of its population. Since the gradual establishment of market economy system in China, hundreds of millions population have flowed into cities from villages, yet they have failed to blend in cities and become migrating population like migratory birds between cities and villages. To investigate Canadian education policy for immigrants will be helpful for in providing beneficial reference and enlightenment to solve the education problem for China's migrating population (especially migrant children) at present.

\section{Review of Chinese and Canadian Immigrant History}

\section{The Immigrant History and Culture of Canada}

The Canadian history itself is a immigrant history, which basically can be divided in several phases: (1) before 1543, Indians and Inuit came to Canada; (2) from 1534 to 1867, the immigrants from France, UK, Europe, Asia were keep increasing; (3) Since 1867, the government has been designedly taking in immigrants initiatively. Especially the two time of immigrant climax from 1901 to 1911 and from 1945 to 1967 brought 800 hundred thousand of immigrants and 1.8 million immigrants, respectively, which greatly relieved the plight of labor shortage. [1]

Although Canadian population is only 30 million, its number of nationality yet ranks top. Only indigenous peoples are already more than 20, while peoples from immigration at modern times are more than 70 . The numerous peoples (including indigenous peoples) within its territory were actually not originated from North America continent, which all migrated from other continents. In other words, there will be no Canada, if there are no immigrants. Immigrants and multi-culture forms the core content of Canadian history.

\section{The Vast Volume of China's Immigrant Wave}

In the 20 years since the start of overflow of migrant laborers in 1990s, the size of migrating population is getting bigger and bigger. Up to the end of 2013, the total migrating population in China is 245 millions, which is more than one sixth of the total population. [2] 
The Research Report of the Condition of Left-behind Children in Rural Area and Migrant Children between Cities and Villages published by ACWF (the All-China Women's Federation ) shows that till October $31^{\text {st }}$, 2010, left-behind children in rural area and migrant children between cities and villages has reached 96 millions, among which left-behind children in rural area is 61.0255 million, accounting for $37.7 \%$ of the total population of children in rural area. The children between 0 and 17 years old migrating with parents reaches 3581, accounting for $62.3 \%$ of the total population of children in rural area at the same ages, [3] which exceeds the total population of Canada by 1.8 million.

\section{Canadian Multi-cultural Education Policy}

After the failure of the policy of assimilation and integrated mode, Canada proposed and started to try multi-cultural education in 1960s and 1970s. In 1971 Prime Minister Trudeau announced to implement bilingual and multi-cultural policy. In 1988 Canadian Multiculturalism Act was passed, recognizing that all Canadian are the full and equal participants in Canadian Society, which marks that the multiculturalism not only rose as federal law, but also become the mainstream ideology for Canadian social culture development and national relation.

\section{The Content of Multi-cultural Education Policy}

Official Language Education Plan for New Immigrants

All students (including new immigrant students) of Canada must receive the education of two official languages, English and French. The purpose is to make new immigrants and ethnical minority students able to effectively use official languages and blend smoothly in Canadian society. In actual practice, the official language education plan is implemented trough class project, mass study project, transitional project and blend-in mainstream culture project and so on. [4]

\section{Culture Preservation Plan}

It is also called ethnical specific education. The purpose is to use non-official languages to make new immigrants and ethnical minority know the cultural heritage of their own nation and preserve the original culture of their nation. [5] By preserving the original culture of new immigrants and ethnical minorities, it is to realize the inheritance of one's own nation and achieve the positive reaction with the multi-culture of Canadian society, bringing out the best in each other.

\section{Trans-culture Education}

New immigrants and ethnical minorities not only need to study, inherit and preserve its own national culture tradition, but also need to transcend cultural barriers and look at and know other people's culture with a equal point of view and realize the fusion of co-existence and development of multi-culture. This plan plays a important role in fostering students' national equality awareness and mentality of openness and inclusiveness.

\section{Antiracism Education}

It is aimed at eliminating the bias and discrimination between peoples and ethnic groups in Canadian society through multi-culture education, especially white people's racial discrimination against colored race and cultivating the national equality awareness among student individuals and social groups.

\section{Implementation Effect of Multi-culture Education Policy}

\section{Enhance National Identity and National Equality}

Canada, as the first nation to advocate and implement multi-culture education policy in the world, has achieved positive effect after 40 year of practice. From national level, this policy plays a constructive role in guarantying basic human right, enhance national identity, alleviating national conflicts, improving national stability and prosperity and national unity. For new immigrants and ethnical minorities, multi-culture education policy recognizes the culture difference and plays a significant role in preserving national culture tradition, eliminating racial discrimination, creating 
national equality and ensuring social status and so on. [6] Therefore, multi-culture education policy is also called the "foundation of state governance" for Canada.

Racial Inequality Still Not Be Eliminated Yet

The problems of racial equality in Canada still exist. The survey shows that $45 \%$ of the respondents clearly think that the discrimination against colored race is always a problem(Ministry of Multiculturalism and Citizenship, 1991). The statistics in 1996 shows that although multi-culture education has been implemented in Canada, America and Australia and some other countries for decades, but discrimination is still worsening, especial racial discrimination. A report from Canadian Race Relations Foundation(CRRF) in 2000 shows that the difference of each nation on aspect of education, employment and income causes the different socioeconomic status that black people, indigenous people and immigrant born in foreign countries face the biggest income gap. [7] Although Canadian Confederation through consistent effort provides diverse education and pursues equality through legislation, however the discrimination and inequality (especially racial discrimination) in realistic society is growing as each day passes.

\section{Policy Change for China's Migrant Children's Education}

The main part of China's migrating population is migrant workers, and the object of education policy takes the under-aged children migrating with their parents as the object, therefore the paper will carry out the discussion centered on migrant children's education policy in the following.

\section{The Development Course of Migrant Children's Education Policy}

The Stage of Policy Vacuum (before 1992)

From 1950s to 1980s, although some peasants went to city for work, but it did not form a large scale and it was mainly individuals. Migrant children's education had not been a social problem back then and the government did not launch any corresponding policies or laws.

The Stage of Policy Restriction (1992-2000)

After the $14^{\text {th }}$ plenary meeting, with the gradually establishment of socialism market economy system, China gradually loosened the restriction on peasants into cities. The number of migrant workers increased exponentially. The immigration of whole family or children migrating with parents increased sharply, which forced the competent department of education launched a series of education policies one after another.

The publishing of Education Policy for School-aged Children and Adolescents among Urban Migrant Population (trial) in 1996 and the publishing of Temporary Policy of Migrant Children and Adolescents' Education confirmed that migrant children could accept education in cities, but the major form was studying at a school on a temporary basis and charged the temporary schooling fee. It is reflected that the government had already started to solve the migrant children's education problem, but showed an obvious attitude of limitedness and discrimination.

The Stage of Policy Correction and Remedy (2001-2005)

The policy with limitedness and discrimination did not only fail to solve the problem completely, but instead brought about new problems. It was needed to corrected in a timely fashion. In 2011, the Decision of the State Council on the Reform and Development of Basic Education confirmed the "two-oriented" policy that it was oriented that government of area receiving immigrant workers to manage the education and it was oriented that full-time public elementary and secondary schools should be the major recipients for migrant children for education, which determined the main responsible and avoid shirking responsibilities. In 2003, Opinion on Further Execute Education for the Children of Migrant Workers confirmed that migrant children were treated equally with urban children and temporary schooling was changed to receiving and it was forbidden to charge temporary schooling fee and the substantial policies for strengthening financial support were launched. In 2005, The notice of State Council on Deepening Reform of Guarantying Mechanism for

Rural Compulsory Education Funds for the first time put forward that it was free for rural compulsory education and confirmed that migrant children share the treatment with urban children. 
The Stage of Equal Rights and Interests and Education Benefits (2006-)

In 2006, Opinion on Solving the Problems of Migrant Workers raised that the compulsory education for migrant workers children should be included in the local education development plan and listed in the education fund budget so as to embody the idea of fairness. Law on Compulsory Education revised in the same year for the first time defined the free of compulsory education in the form of legislation and enhanced guarantee for migrant children's education, which marked the change of education benefit policy from remedy mode to system mode. Layout Plan of China's Medium and Long Term Education Reform and Development strengthened the equal rights of migrant children for receiving education.

\section{The Transformation of Leading Idea of Education Policy}

From the overall review of the transformation of education policy on migrant children's education, it is able to clearly map out the transformation course of policy from policy vacuum in 80 s to restriction and discrimination in 90 to policy correction and remedy stage in the beginning of $21^{\text {st }}$ century to the policy idea with the gist of equal rights and interest and education benefits in recent decade.

It should be seen that letting migrant children to receive equal education and share the same treatment with urban children has become the dominant idea of today's policy. The relevant policy more and more reflect social fairness as well as the nation's assistance and remedy to social disadvantage group. The humanistic concern of the policy is manifested. Generally speaking, under the guarantee of national constitution and relevant laws, there will be more and more guarantees for the education right of migrant children.

\section{Comparative Thinking on Education Policy for Trans-culture Immigrants}

\section{Relative Unity of Policy Target}

Canada based on its national conditions, pioneered multi-culture education after the failure of trial implementation of national assimilation and integration policy. The practice shows that decades of implementation of multi-culture education policy lays a good policy foundation for improving national identity, maintaining racial equality and realizing social stability and unity and promotes the continuing improvement of overall strength of Canada.

Facing the sudden migrant workers wave, China launched a series of relevant education policy and its thought was changed from passive to initiative, from restrict to open, from discrimination to equality, from management to service, which reflects the consistent improvement of social management capacity and provides institutional guarantee for personal rights and interests, family development, social harmony and national stability.

Now matter it's the Canadian multi-culture education policy or China's stable-improved education policy in accordance with reality, their targets are both to achieve national stability, social harmony, racial equality and rights guarantee, but adopt different policy mode and implementation path based on the difference of national conditions .

\section{The Multi-dimensional Reason for Policy Difference}

The difference between China and Canada on education policy is various, which mainly is:

Firstly, the attitude toward immigrants is different based on national conditions

Immigrants are vital for promoting Canadian economy and social development and are very important resources. In the past 15 years, the federal government's annual immigrant quota of 250 thousand at average accounts for 76.24\% of Canadian annual population increase, which is enough to prove immigrants promoting function for Canadian economy. In 2015, the immigrant quota is further increased to 260 thousand to 285 thousand, which is mainly to response the labor force and technology shortage in Canadian economy growth strategy. [8] 
China does not lack of labor force for a long time, in contrary, solving migrant children's education problem seems to be a forced and helpless option, which makes the already limited public resources even more strained. Given this, the mentality of rejecting and boycotting migrant population has always been on the mind of city administrators and urban residents. Being reflected on policy making is to set multiple obstacles for migrant workers entering cities and meanwhile migrant population can not enjoy the same guarantee of rights, interests and benefits and so on as the city dwellers.

Secondly, it is the difference of two countries concerning history evolution and culture type

The Canadian history is an immigrant history. Multi-culture education is the outcome of era development of Canada. The ultimate target is to eliminate racial discrimination, promote the equal cooperation between nations and realize prosperity and development of multi-culture society. [9] Multi-culture education is blended in school education, family education and even daily social life.

China, in the transitional period, shows the conflicts and blending of urban culture and village culture on the aspect of immigrant integration. When migrant population enters into cities, they inevitably will bring in village culture, but village culture is at a non-equivalent status in face of powerful urban culture and is rejected or discriminated. But in the process of immigrants blending in cities, they are not simply assimilated by urban culture, yet it is a process of frequent interaction and interpenetrating of urban culture and village culture.

Lastly, it is the difference of the system design of national system

Canada is made up by 10 provinces and 3 regions, with a total population of 35 million. In its 150 years' history, there is never the urban-rural dualism. Its difference between urban and rural is not big.

The household registration system implemented since 1950s in China divides the population into agricultural population and non-agricultural population and strictly control peasants migrating to cities. This system divides cities and villages as different system regions. The agricultural population can not mobilize freely, nor share the equal social insurance and benefits as city residents. Although Chinese government cancelled urban-rural dualism in 2014, yet its influence is not eliminated immediately. It will take up to decades to gradually realize same rights between urban and rural residents.

\section{Acknowledgments}

This paper is a project supported by the Fundamental Research Funds for the Central Universities and the project name is The Social Identity and Identity Construction of New Generation of Migrant Workers, and its project number is: RW150112.

\section{References}

[1] Zheng rong Li. Review on Canadian Immigrant Policy and Multiculturalism. Journal of Hubei Normal University(Philosophy and Social Science),2001(4):61-63

[2] Development Report of Chinese Migrating Population: the migrating population will reach 245 million by 2013, Xin Hua News http :/ /politics . people. com.cn /n/2014/1118 /c7073126049102.html

[3] ACWF ( the All-China Women's Federation ): the left-behind children in the rural areas in China reaches 60 million, Xin Hua News http :// news. xinhuanet. com/ politics /2013-05/ 10/c_115720450. htm

[4] Chenglong Luo: Canadian Education for National Minorities and Multi-culture Policy ,1997(3):91-94 
[5] Beier Bai, The enlightenment of Canadian multi-cultural education on China's national education. Journal of Qinghai Normal University(philosophy and social science) ,2012(2):117-121

[6] Jianguo Gao. Evaluation and analysis on Canadian multi-culture policy. World Ethno-National Studies,1999(4):30-40

[7] Ratna Ghosh. Public Education And Multicultural Policy in Canada: the Special Case of Quebec. International Review of Education , 2004 , Volume 50, Issue 5/6,543 - 566

[8] http://canada.fang.com/news/14257424.htm

[9] Feng Wei, Hong Cai, Yuanquan Yao The enlightenment of Canadian multi-cultural education on China’s multi-culture education. Elementary \& Secondary Schooling Abroad 2011(6):62-65 